\title{
Caspase-mediated cleavage of the U snRNP-associated Sm-F protein during apoptosis
}

\author{
KCR Malmegrim de Farias ${ }^{1,2}$, X Saelens ${ }^{3}$, GJM Pruijn ${ }^{1}$, \\ $P$ Vandenabeele ${ }^{3}$ and WJ van Venrooij ${ }^{\star, 1}$ \\ 1 Department of Biochemistry, Nijmegen Center for Molecular Life Sciences, \\ University of Nijmegen, NL-6500 HB, Nijmegen, The Netherlands \\ 2 Department of Clinical Medicine, Division of Clinical Immunology, Faculty of \\ Medicine of Ribeirão Preto, University of São Paulo, 14051-140 Ribeirão \\ Preto, Brazil \\ ${ }^{3}$ Department of Molecular Biomedical Research, Flanders Interuniversity \\ Institute for Biotechnology and Ghent University, B-9000 Ghent, Belgium \\ * Corresponding author: WJ van Venrooij, Department of Biochemistry 161, \\ Nijmegen Center for Molecular Life Sciences, University of Nijmegen, PO box \\ 9101, NL-6500 HB Nijmegen, The Netherlands. Tel: +31 2436136 56; Fax: \\ +3124 35405 25; E-mail: W.vanvenrooij@ncmls.kun.nl
}

Received 30.10.02; revised 14.11.02; accepted 20.11.02 Edited by GM Cohen

\begin{abstract}
Recent studies have implicated the dying cell as a potential reservoir of modified autoantigens that might initiate and drive systemic autoimmunity in susceptible hosts. The spliceosomal $\mathrm{Sm}$ proteins are recognized by the so-called anti-Sm autoantibodies, an antibody population found exclusively in patients suffering from systemic lupus erythematosus. We have studied the effects of apoptosis on the Sm proteins and demonstrate that one of the Sm proteins, the $\mathrm{Sm}-\mathrm{F}$ protein, is proteolytically cleaved in apoptotic cells. Cleavage of the $\mathrm{Sm}-\mathrm{F}$ protein generates a 9-kDa apoptotic fragment, which remains associated with the $U$ snRNP complexes in apoptotic cells. Sm-F cleavage is dependent on caspase activation and the cleavage site has been located near the C-terminus, EEED ${ }^{81} \downarrow$ G. Use of different caspase inhibitors suggests that besides caspase-8 other caspases are implicated in Sm-F cleavage. A C-terminally truncated mutant of the Sm-F protein, representing the modified form of the protein, is capable of forming an Sm E-F-G complex in vitro that is recognized by many anti-Sm patient sera.

Cell Death and Differentiation (2003) 10, 570-579. doi:10.1038/ sj.cdd.4401196
\end{abstract}

Keywords: apoptosis; autoimmunity; caspase cleavage; Sm autoantigen; SLE; U snRNPs

Abbreviations: Ac, acetyl; CMK, chloromethylketone; DMSO, dimethyl sulfoxide; DTE, dithioerythreitol; DTT, dithiothreitol; FMK, fluoromethylketone; MAb, monoclonal antibody; FADD, Fas-associated death domain; FCS, fetal calf serum; NP-40, Nonidet P40; PAGE, polyacrylamide gel electrophoresis; PMSF, phenylmethylsulfonylfluoride; SDS, sodium dodecyl sulfate; SLE, systemic lupus erythematosus; $U$ snRNP, uridine-rich small nuclear ribonucleoprotein; TMG, 2,2,7-trimethylguanosine; Z, benzyloxycarbonyl.

\section{Introduction}

Systemic autoimmune diseases are characterized by the production of autoantibodies directed towards a wide range of self-antigens. The mechanisms by which these autoantigens escape immunological tolerance are still largely unknown, although a number of recent observations suggest that modified self-antigens that are generated during cell death, apoptosis ${ }^{1-7}$ or necrosis, ${ }^{8}$ may play an important role in the development of autoimmunity. In the past few years, many proteins and protein complexes that are autoantigenic in autoimmune patients have been described to be uniquely modified during apoptosis. ${ }^{3}$ The best-characterized type of modification of autoantigenic proteins that occurs during apoptosis is proteolytic cleavage, which is largely mediated by caspases ${ }^{9,10}$ or by granzyme B. ${ }^{11-13}$

Other post-translational modifications of autoantigens that occur during apoptosis have been described, such as hyperphosphorylation, dephosphorylation, citrullination, crosslinking by transglutaminase, poly(ADP-ribosyl)ation, methylation, and deacetylation, (reviewed in Utz and Anderson $^{1}$, Utz et al. ${ }^{3}$, Doyle and Mamula ${ }^{7}$ ). It has been postulated that such post-translational modifications of autoantigens may uncover cryptic epitopes and/or create novel epitopes to which no tolerance exists, and in this way could provoke an autoimmune response in susceptible individuals. ${ }^{1-6}$ Based on this hypothesis, the modifications brought upon autoantigens during cell death represent the initial epitopes to which a primary immune response is generated. This response is followed by secondary responses and epitope spreading to unmodified regions of the autoantigens and antigens associated with the initially modified antigen. ${ }^{6}$

Patients suffering from systemic lupus erythematosus (SLE) spontaneously produce autoantibodies against a multitude of cellular components. Antibodies against the spliceosomal Sm proteins, the so-called anti-Sm autoantibodies, are SLE-specific, in contrast to most other SLE-associated autoantibody populations. ${ }^{14}$ The $\mathrm{Sm}$ proteins B/B', D1, D2, $D 3, E, F$, and $G$ are core components of the small nuclear ribonucleoproteins (snRNPs) U1, U2, U4/U6, and U5, which are essential for the splicing of pre-mRNAs in eukaryotes. ${ }^{15}$ The parallel recognition of several $\mathrm{Sm}$ proteins by anti-Sm patient sera is not only due to distinct antibody populations, but also to cross-reactive epitopes on the Sm proteins, thus indicating that the Sm proteins share structural homology. Indeed, all Sm proteins contain an evolutionarily conserved region of 70-90 amino acids, designated Sm domain, which contains the Sm1 and the Sm2 sequence motifs. $^{16}$

In immunoblotting, anti-Sm autoantibodies react predominantly with the $\mathrm{Sm}$ proteins $\mathrm{B} / \mathrm{B}^{\prime}, \mathrm{D} 1, \mathrm{D} 3$, and, to a lesser extent, D2. ${ }^{17}$ Only a few sera also react with denatured Sm proteins $E, F$, or $G$ on immunoblots. ${ }^{18}$ However, it has been shown that anti-Sm SLE patient sera efficiently and specifi- 

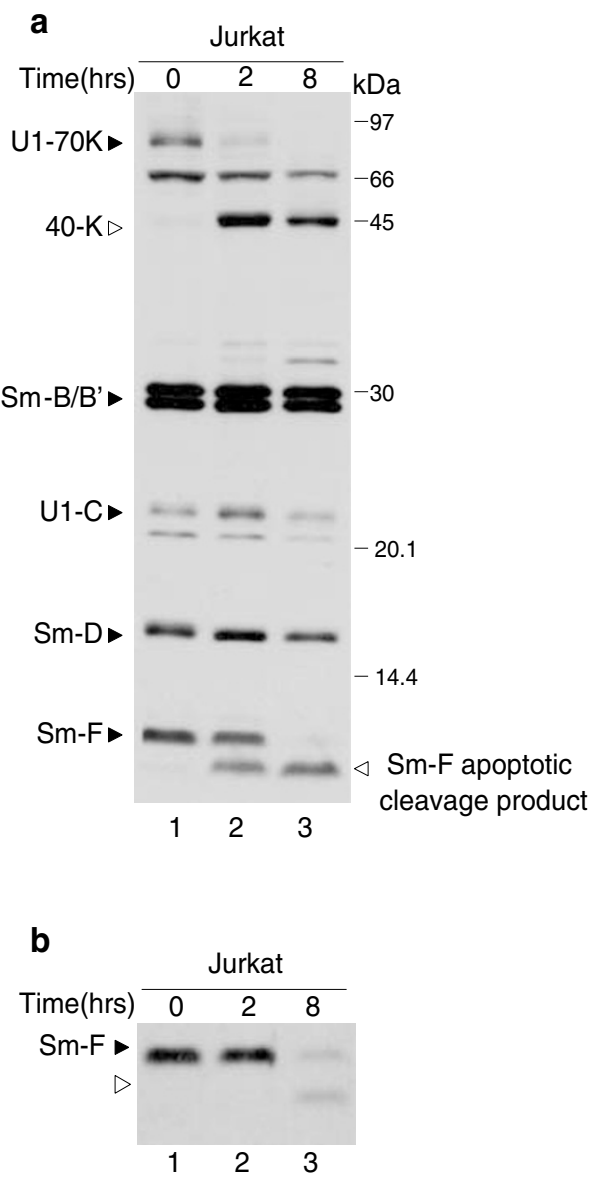
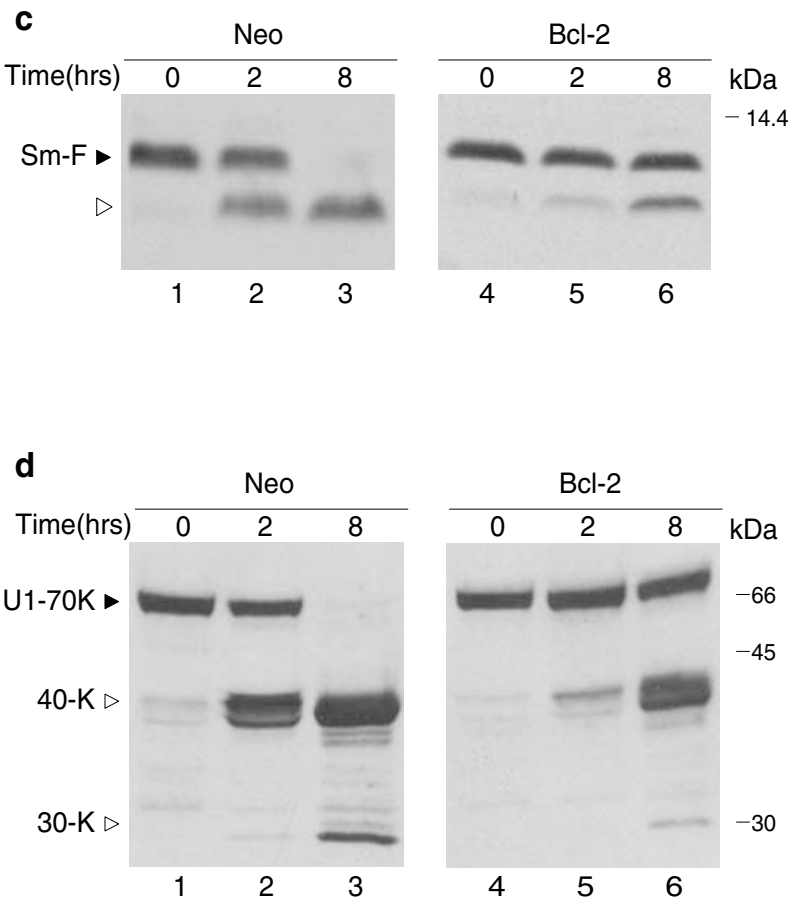

Figure 1 Cleavage of the Sm-F protein during anti-Fas-induced apoptosis. (a) Jurkat cells were treated with the anti-Fas monoclonal antibody $7 \mathrm{C} 11$ for the indicated time periods. Protein extracts were analyzed by $15 \%$ SDS-PAGE and Western blotting using the anti-Sm patient serum B156. (b) Jurkat/Neo cells were treated with the anti-Fas monoclonal antibody 7C11 for the indicated time periods. Protein extracts were analyzed by $15 \%$ SDS-PAGE and Western blotting using an anti-Sm-F polyclonal rabbit serum. (c,d) Jurkat/Neo and Jurkat/Bcl-2 were treated with the anti-Fas monoclonal antibody $7 \mathrm{C} 11$ for the indicated time periods. Protein extracts were analyzed by $15 \%$ SDS-PAGE and Western blotting using the anti-Sm patient serum B156 (c) or the anti-U170K patient serum H42 (d). The positions of molecular weight markers are indicated on the right and the designations of the immunostained proteins on the left. Closed arrowheads, full-length protein; open arrowheads, cleavage products

cally immunoprecipitate the E-F-G ternary complex. ${ }^{19}$ Therefore, it was concluded that the $E, F$, and $G$ proteins might harbor immunodominant antigenic determinants that are expressed exclusively or predominantly on the assembled E-F-G complex. ${ }^{19}$

At present, no modifications specifically occurring on the Sm proteins during apoptosis have been reported. In this study, we demonstrate that the Sm-F protein is cleaved during apoptosis. Furthermore, the role of caspases in Sm-F cleavage was investigated and the cleavage site mapped. The possible consequences of the apoptotic modification of a Sm protein for the generation of anti-Sm autoantibodies in SLE patients are discussed.

\section{Results}

\section{Cleavage of the Sm-F protein during anti-Fas induced apoptosis}

In order to study potential molecular changes in the Sm proteins during apoptosis, Jurkat cells were treated with the agonistic anti-Fas antibody 7C11 and analyzed by Western blotting using different anti-Sm patient sera or polyclonal rabbit antisera raised against individual $\mathrm{Sm}$ proteins. Sm-B/B', $D, E$, and $G$ proteins were not detectably altered during antiFas induced apoptosis (Figure 1a and data not shown). However, using the patient serum B156, which recognizes the $\mathrm{Sm}-\mathrm{F}$ protein $(11 \mathrm{kDa})$ in immunoblot, an Sm-F-specific band with an apparent molecular weight of 9-kDa was observed, which would be consistent with proteolytic cleavage of Sm-F protein (Figure 1a). The B156 serum has an anti-U1RNP/antiSm serotype ${ }^{14}$ recognizing the specific U1 proteins, U1-70K and U1C, and the Sm-B/B' ${ }^{\prime}, \mathrm{Sm}-\mathrm{D}$, and Sm-F proteins. The identity of the Sm-F protein was confirmed by Western blot analysis using a specific anti-Sm-F polyclonal rabbit serum (Figure 1b). Interestingly, the anti-Sm-F rabbit serum displayed a relatively weak reactivity with the $9-\mathrm{kDa} S m-F$ species in apoptotic cell extracts (Figure 1b, lanes 2 and 3 ).

To support the correlation between $\mathrm{Sm}-\mathrm{F}$ cleavage and execution of the apoptotic cascade after Fas stimulation, we compared the appearance of the Sm-F 9-kDa fragment in cell lysates derived from Fas-stimulated Jurkat cells (Jurkat/Neo) 
and cells overexpressing Bcl-2 (Jurkat/Bcl-2). As expected, apoptosis after anti-Fas treatment was strongly delayed in Jurkat/Bcl-2 as compared to Jurkat/Neo. ${ }^{20-23}$ In Jurkat/Neo cell lysates, the conversion of Sm-F into a 9-kDa fragment was clearly detectable after $2 \mathrm{~h}$ of anti-Fas treatment and was complete after $8 \mathrm{~h}$ of anti-Fas treatment (Figure 1c, lanes 13). In contrast, in anti-Fas treated Jurkat/Bcl-2 cells, the 9-kDa $\mathrm{Sm}-\mathrm{F}$ fragment was only detectable after $8 \mathrm{~h}$ and represented only a minor fraction of the total amount of Sm-F protein (Figure 1c, lanes 4-6). U1-70K protein is one of the prototypic autoantigens known to be cleaved during apoptosis. ${ }^{21}$ Therefore, we compared the fate of Sm-F and U1-70K proteins in the same apoptotic lysates, using a patient serum reactive with $U 1-70 K{ }^{22,23}$ As shown in Figure 1d, cleavage of the U1$70 \mathrm{~K}$ protein into a $40 \mathrm{kDa}$ fragment was observed with the same kinetics after Fas-ligation as the cleavage of Sm-F protein.
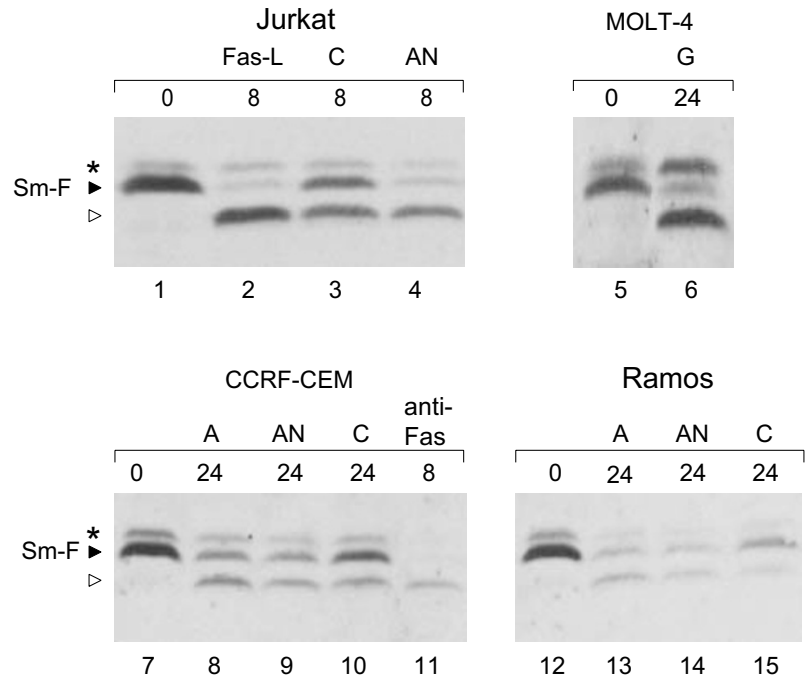

Figure 2 Cleavage of the Sm-F protein in various cell types treated with different apoptosis inducers. Cells (Jurkat, MOLT-4, CCRF-CEM, and Ramos) were treated with anti-Fas mAb, Fas-ligand (Fas-L), anisomycin (AN), cycloheximide $(\mathbf{C})$, actinomycin $D(\mathbf{A})$, or gamma irradiation $(\mathbf{G})$ for the indicated time periods (in h). Protein extracts were analyzed by $15 \%$ SDS-PAGE and Western blotting using the anti-Sm patient serum B156. The band indicated with an asterisk on the left is the Sm-E protein, which is weakly recognized by patient serum B156. Closed arrowheads, full-length protein; open arrowheads, cleavage product

\section{A variety of apoptosis stimuli lead to Sm-F cleavage in various cell types}

To investigate whether cleavage of the Sm-F protein is a general feature of apoptotic cells, we analyzed cell lysates from several cell types exposed to different apoptotic stimuli. Jurkat cells were exposed to Fas-ligand, cycloheximide, or anisomycin (Figure 2, lanes 1-4), MOLT-4 cells to gamma irradiation (Figure 2, lanes 5-6), CCRF-CEM cells to actinomycin $\mathrm{D}$, anisomycin, cycloheximide, or anti-Fas antibody (Figure 2, lanes 7-11), a B cell line (Ramos Burkitt lymphoma) to actinomycin $\mathrm{D}$, anisomycin, or cycloheximide (Figure 2, lanes 12-15), and HeLa and HEp-2 cells to TNF- $\alpha$ or anti-Fas in combination with actinomycin D (data not shown). Cleavage of $\mathrm{Sm}-\mathrm{F}$ protein was observed in all apoptotic cells analyzed, suggesting that this cleavage is a common feature of the apoptotic execution process.

\section{Sm-F cleavage product remains associated with the $U$ snRNP complexes in apoptotic cells}

To investigate whether the Sm-F cleavage product remains associated with the U snRNP complexes in apoptotic cells, we immunoprecipitated these complexes from control and apoptotic Jurkat cell extracts using monoclonal antibodies directed to the U1 snRNP-specific proteins U1A (mAb 9A9, which also recognizes $\mathrm{U}_{2} \mathrm{~B}^{\prime \prime}$ ) and $\mathrm{U} 1-70 \mathrm{~K}(\mathrm{mAb} 2.73)$, to the $\mathrm{Sm}$ proteins (mAb Y12), to Sm-D1 (mAb KSm2), to U2B" (mAb 4G3) and polyclonal antibodies to the TMG-cap of the snRNAs (H20). Immunoprecipitates were subsequently analyzed by immunoblotting using the anti-Sm patient serum B156. In all cases, the Sm-F cleavage product was found in the immunoprecipitate (Figure 3). This indicates that the Sm-F protein is cleaved while associated with the intact $U$ snRNP complexes in apoptotic cells and remains associated with these complexes. Neither Sm-F nor its cleavage product was precipitated by a control antibody (anti-Ro60, lanes 15 and 16).

\section{Sm- $F$ cleavage is caspase-mediated}

Since the activation of caspases is one of the major biochemical features of the execution phase of apoptosis, we investigated whether caspase activation was required for $\mathrm{Sm}-\mathrm{F}$ cleavage. Jurkat cells were cultured in the presence of



Figure 3 The apoptotic cleavage product of Sm-F remains associated with the $U$ snRNP complexes. $U$ snRNP complexes were immunoprecipitated from control and apoptotic ( $8 \mathrm{~h}$ incubated with anti-Fas antibody) Jurkat cell extracts using anti-TMG cap rabbit serum (H2O) and the monoclonal antibodies Y12 (anti-Sm), 2.73 (anti-U170K), KSm2 (anti-Sm-D1), 9 A9 (anti-U1A/U2B"), 4G3 (anti-U2B"), and 1D11 (anti-Ro60). Immunoprecipitates were analyzed by 15\% SDS-PAGE and Western blotting using the anti-Sm patient serum B156. The positions of the Sm-F protein (closed arrowhead) and its cleavage product (open arrowhead) are indicated on the left. In lanes 1 and 2 input samples, $20 \%$ of the total control and apoptotic cell extracts, respectively, were loaded 


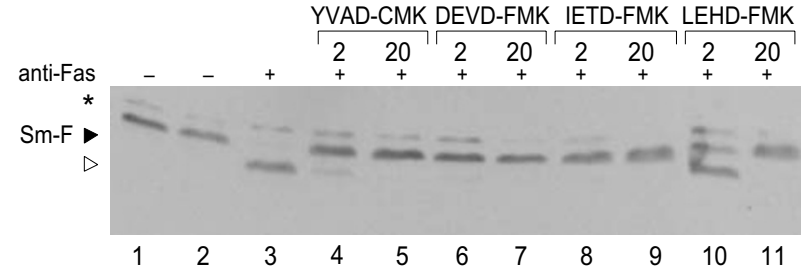

Figure 4 Inhibition of Sm-F cleavage by caspase inhibitors. Jurkat cells were incubated for $1 \mathrm{~h}$ at $37^{\circ} \mathrm{C}$ in the presence of four cell-permeable tetrapeptide caspase inhibitors: $2 \mu \mathrm{M}$ (lanes $4,6,8,10$ ) or $20 \mu \mathrm{M}$ (lanes $5,7,9,11$ ) of caspase inhibitors YVAD-CMK, DEVD-FMK, IETD-FMK, and LEHD-FMK. Subsequently, cells were cultured for $8 \mathrm{~h}$ in the presence of anti-Fas mAb. In lane 1 contro extract from Jurkat cells incubated with $2 \%$ DMSO instead of caspase inhibitors was loaded. In lanes 2 and 3 extracts from control and apoptotic ( $8 \mathrm{~h}$, anti-Fas $\mathrm{mAb}$ ) Jurkat cells, respectively, were analyzed. Total protein extracts were analyzed by $15 \%$ SDS-PAGE and Western blotting using the anti-Sm patient serum B156. The positions of the Sm-F protein (closed arrowhead) and its cleavage product (open arrowhead) are indicated on the left. The band indicated with an asterisk on the left is the Sm-E protein, which is weakly recognized by the anti-Sm patient serum B156

various tetrapeptide inhibitors of caspases for $1 \mathrm{~h}$ prior to the induction of apoptosis by the addition of anti-Fas antibody, after which cells were cultured for $8 \mathrm{~h}$. We used caspase inhibitors that are representative for the different groups of caspases: Ac-YVAD-CMK for group I caspases (caspase-1like), z-DEVD-FMK for group II caspases (caspase-3-like), or Z-IETD-FMK (caspase-8) and Z-LEHD-FMK (caspase-9) for group III caspases. Cell extracts were analyzed by Western blotting using the anti-Sm patient serum B156. The cleavage of Sm-F was (almost) completely inhibited in the presence of 2 or $20 \mu \mathrm{M}$ of Ac-YVAD-CMK, Z-DEVD-FMK, or Z-IETD-FMK inhibitors (Figure 4, lanes 4-9). In the presence of the ZLEHD-FMK inhibitor Sm-F cleavage was partially inhibited at $2 \mu \mathrm{M}$ and almost completely inhibited in the presence of a 10fold higher concentration (Figure 4, lanes 10-11). As a control for the inhibitory activity of the tetrapeptide inhibitors, cell extracts were also analyzed for U1-70K cleavage. ${ }^{22}$ The inhibition of U1-70K cleavage appeared to be very similar to that observed for Sm-F (data not shown). These results suggest that different caspases or proteases activated by caspases are involved in Sm-F cleavage in apoptotic Jurkat cells.

In another approach to examine if caspases are crucial for $\mathrm{Sm}-\mathrm{F}$ cleavage, we analyzed the fate of Sm-F in a cellular model of caspase-independent necrotic cell death ${ }^{24,25}$ using Jurkat JB6 cells ${ }^{26}$ that die necrotically when treated with dsRNA. ${ }^{27}$ No cleavage of Sm-F was observed in these cells, indicating that $\mathrm{Sm}-\mathrm{F}$ is not the result of mere cell demise and supporting the involvement of caspases in the cleavage of the $\mathrm{Sm}-\mathrm{F}$ protein rather than another proteolytic system active in necrotic cell death (data not shown).

To determine whether recombinant caspases can process the Sm-F protein, in vitro translated ${ }^{35} \mathrm{~S}$-labeled $\mathrm{Sm}-\mathrm{F}$ was incubated with recombinant murine caspases-1, -2, -3, -6, -7, 8 and $-11 .^{28}$ Reaction products were analyzed by SDSpolyacrylamide gel electrophoresis (PAGE) followed by autoradiography. Caspases- 1 and -8 , but not $-2,-3,-6,-7$ and -11 , cleaved the $S m-F$ protein, generating a $9-\mathrm{kDa}$ cleavage product, with an electrophoretic mobility indistinguishable from that of the Sm-F fragment in apoptotic cell extracts (Figure 5a and data not shown). Caspase-1 induced only a weak cleavage of $\mathrm{Sm}-\mathrm{F}$, while caspase-8 was much more efficient (Figure 5a, lanes 2 and 7 ). In vitro cleavage of ${ }^{35}$ S-labeled PARP was performed as a control for the activity of the recombinant caspases (Figure 5a, lanes 9-16). All the caspases cleaved PARP except caspase-2, which was checked to be active with an Ac-DEVD-amc fluorogenic substrate $^{28}$ (data not shown). To evaluate the difference in activity of caspases- 1 and -8 (and caspase-3 as a negative control) on the Sm-F protein more extensively, a dilution series of these caspases was incubated for $1.5 \mathrm{~h}$ with radiolabeled Sm-F or PARP. The results in Figure $5 \mathrm{~b}$ show that caspase-8 was about 10 times more efficient than caspase-1 in cleaving the Sm-F protein (lanes 2-7), whereas the efficiency of PARP cleavage was about equal (lanes 13-18).

Taken together these data indicate that $\mathrm{Sm}-\mathrm{F}$ is a caspase substrate and that in vitro caspase-8 cleaves Sm-F most efficiently. To verify if caspase- 8 is crucial for the processing of Sm-F in apoptotic cells, we made use of caspase-8deficient Jurkat cells, as confirmed by immunoblotting (data not shown). These cells respond apoptotically when treated with staurosporine in combination with cycloheximide. Despite the absence of caspase-8, the same Sm-F cleavage pattern was observed as in staurosporin-treated parental cells (Figure 5c, lanes 3-4). From this, we concluded that other caspases than caspase-8 can cleave Sm-F in apoptotic cells, in agreement with the in vitro proteolysis results using recombinant caspases.

\section{Identification of the caspase cleavage site in Sm-F}

Analysis of the Sm-F sequence (Figure $6 \mathrm{a}$ ) revealed the presence of three potential caspase cleavage sites, two of which are located near the middle of the primary structure and the third located close to the C-terminus. Taking into account the apparent size of the cleavage product, we speculated that the ${ }^{78}$ EEED ${ }^{81}$ sequence near the C-terminus of $\mathrm{Sm}-\mathrm{F}$ is the most likely target for caspases. Indeed, the substitution of aspartic acid 81 by an alanine confirmed this hypothesis, because this mutant of $\mathrm{Sm}-\mathrm{F}$ was neither cleaved by recombinant caspase-1 nor by caspase-8 in vitro, in contrast to wild-type Sm-F (Figure 6b). A C-terminally truncated mutant of the Sm-F protein comprising amino acids 1-81, which was analyzed in parallel with the in vitro cleaved Sm-F (Figure 6b, lane 9), co-migrated with the Sm-F fragment generated by caspase cleavage, consistent with cleavage at aspartate-81. Taken together, these data indicate that the ${ }^{78}$ EEED $^{81}$ sequence indeed represents the caspase cleavage site in the Sm-F protein.

\section{Anti-Sm patient sera recognize the Sm-F apoptotic fragment individually and assembled into a complex with the Sm-E and Sm-G proteins}

To investigate whether the apoptotic Sm-F cleavage product is recognized by anti-Sm patient sera that are not reactive with the Sm-F protein on immunoblots, we used the in vitro translated Sm proteins E, F, G, and the C-terminal deletion 
a
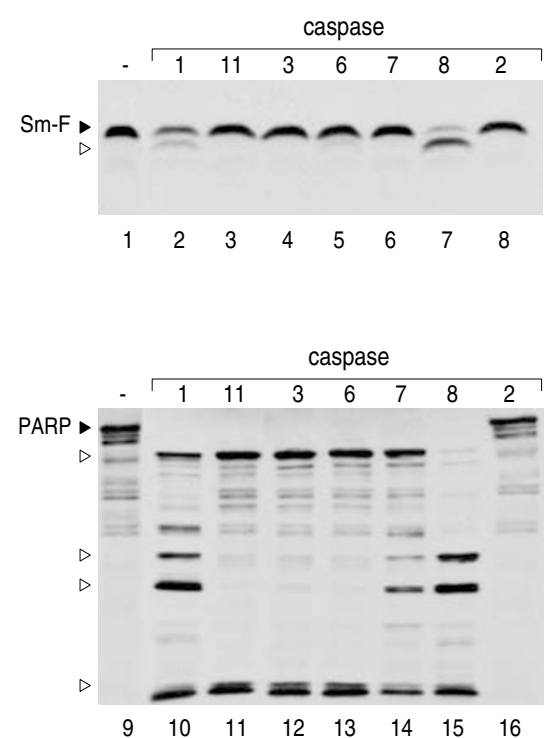

C

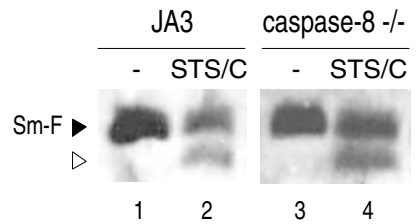

b
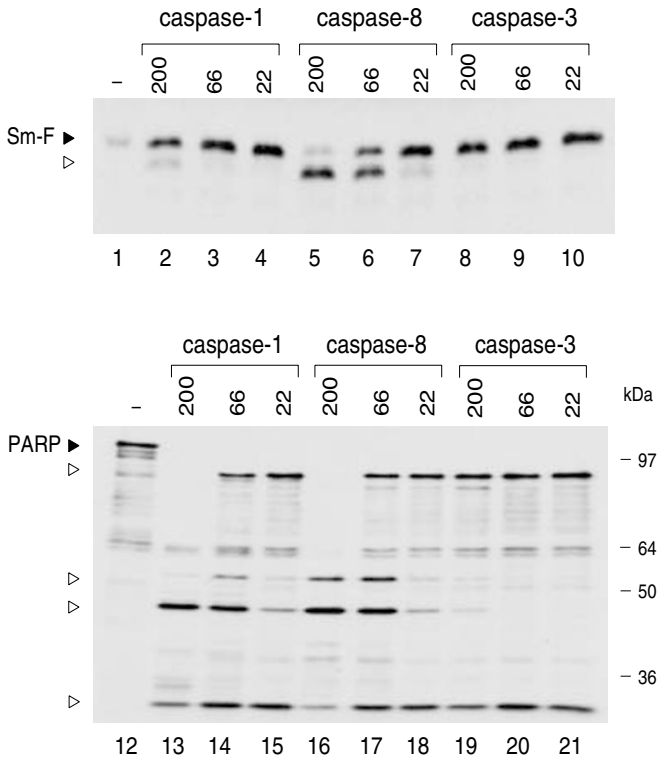

Figure 5 Cleavage of Sm-F by recombinant caspases. In vitro translated ${ }^{35} \mathrm{~S}$-labeled Sm-F (upper panel) or PARP (lower panel) was incubated with $200 \mathrm{nM}$ of purified murine recombinant caspases-1, $-11,-3,-6,-7,-8$, or -2 (a) or with 200,66 , or $22 \mathrm{nM}$ of caspases $-1,-8$, or $-3(\mathbf{b})$ for $1.5 \mathrm{~h}$ at $37^{\circ} \mathrm{C}$. The resulting reaction products were analyzed by $15 \%(\mathrm{Sm}-\mathrm{F})$ or $10 \%$ (PARP) SDS-PAGE, followed by autoradiography. In the first lane of each panel, the mock-incubated protein was loaded. Closed arrowheads, full-length protein; open arrowheads, cleavage products. (c) Cleavage of Sm-F in caspase-8-deficient Jurkat cells. Control JA3 cells and caspase-8deficient Jurkat cells were treated with or without staurosporin (STS) and cycloheximide (C) for $8 \mathrm{~h}$. Protein extracts were analyzed by $15 \%$ SDS-PAGE and Western blotting using the anti-Sm patient serum B156. Closed arrowheads, full-length protein; open arrowheads, cleavage product

mutant $\mathrm{F} \Delta 81$ for immunoprecipitation experiments. ${ }^{35} \mathrm{~S}-\mathrm{la}-$ beled in vitro translated proteins were incubated individually (Figure $7 \mathrm{~b}-\mathrm{h}$, lanes 1-4) or combined to allow E-F-G complex formation $^{19}$ (Figure $7 \mathrm{~b}-\mathrm{h}$, lanes 5 and 6 ), and subsequently immunoprecipitated with preselected anti-Sm patient sera, with the anti-Sm Y12 mAb or with a nonimmune serum. Interestingly, the Sm-F C-terminally truncated mutant was able to assemble into a complex with the $E$ and $G$ proteins in vitro (designated $\mathrm{E}-\mathrm{F}^{*}-\mathrm{G}$ complex). The results in Figure 7 show that all the sera tested were able to precipitate the individual proteins as well as the $E-F-G$ and $E-F^{*}-G$ complexes. However, as reported previously, ${ }^{19}$ most anti$\mathrm{Sm}$ patient sera and $\mathrm{mAb}$ Y12 precipitated the $\mathrm{E}-\mathrm{F}-\mathrm{G}$ complex (and the $\mathrm{E}-\mathrm{F}^{*}-\mathrm{G}$ complex) considerably more efficiently than the individual proteins, suggesting that an important subset of anti-Sm patient autoantibodies recognizes conformational epitopes located on the E-F-G (or E$F^{\star}-G$ ) complex itself. In total, 25 anti-Sm patient sera were tested for their ability to immunoprecipitate the E-F-G and the $E-F^{*}-G$ complexes. Although differences in precipitating efficiency between the various sera were observed, the overall result was that no significant differences in precipita- tion efficiency of both complexes were observed (Figure $7 b-g$, lanes 5 and 6 , and data not shown).

\section{Discussion}

In the past few years, a role for apoptosis in the development of autoimmunity has been suggested. At present, many autoantigens have been found that are modified during apoptosis. ${ }^{3}$ A current hypothesis is that these intracellularmodified autoantigens become exposed to the immune system because of massive cell death and/or inefficient removal of dying cells, leading to a specific primary immune response against the modified epitopes of the self-antigens, followed by secondary responses and epitope spreading to unmodified regions of the autoantigens and antigens associated with the initially modified antigen. ${ }^{1,2,6}$ SLE patients develop autoantibodies against a wide variety of intracellular antigens such as the components of the U1 snRNP complex, including the spliceosomal Sm proteins. ${ }^{14}$ In this report, we demonstrate for the fist time that one of the Sm proteins, the $\mathrm{Sm}-\mathrm{F}$ protein, is cleaved in apoptotic cells in a caspase- 
a

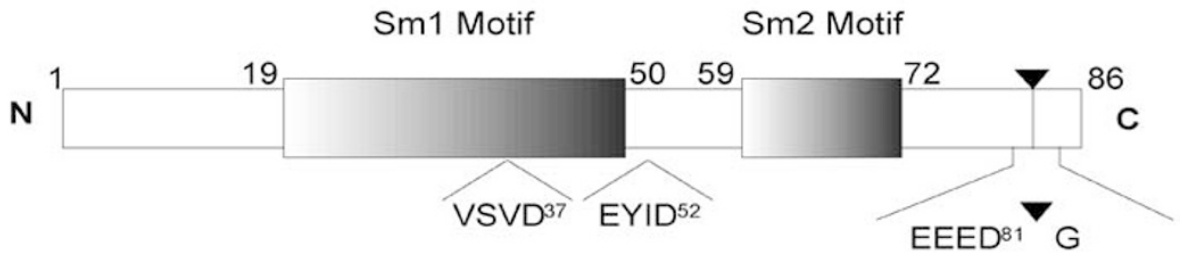

b

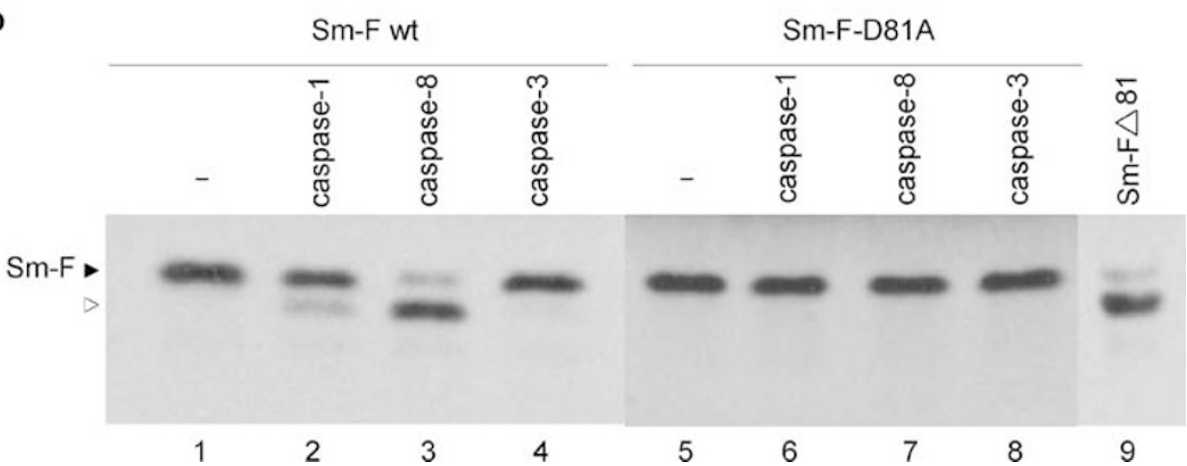

Figure 6 Mapping of the caspase cleavage site on Sm-F. (a) Schematic representation of the primary structure of Sm-F. The relative positions of the Sm1 and Sm2 motifs and the putative caspase cleavage sites are indicated. (b) In vitro translated ${ }^{35} \mathrm{~S}$-labeled Sm-F (Sm-F wt) or Sm-F-D81A was incubated without or with $200 \mathrm{nM}$ of purified murine recombinant caspases- $1,-8$, or -3 for $1.5 \mathrm{~h}$ at $37^{\circ} \mathrm{C}$. Reaction products were analyzed by $15 \%$ SDS-PAGE, followed by autoradiography. Closed arrowhead, full-length protein; open arrowhead, cleavage product

dependent way, generating a 9-kDa apoptotic product. The intact and the apoptotic form of Sm-F are recognized by antiSm sera from patients suffering from SLE as demonstrated by immunoblot and immunoprecipitation studies.

By analyzing the U1 snRNP complex during anti-Fas induced apoptosis, we demonstrated that it is likely that the $\mathrm{Sm}-\mathrm{F}$ protein is cleaved while it is associated with the intact $\mathrm{U} 1$ snRNP complex in apoptotic cells, and that the N-terminal 9$\mathrm{kDa}$ fragment remains associated with the U1 snRNP complex. The conserved $\mathrm{Sm}$ motif in the Sm-F protein, composed of Sm1 (position 19-50) and Sm2 (position 59-72) motifs, ${ }^{16}$ mediates the Sm-F interaction with the $U$ snRNA's Sm site. ${ }^{15}$ Cleavage of $\mathrm{Sm}-\mathrm{F}$ after the aspartic residue at position 81 , as deduced from the in vitro cleavage experiments using recombinant caspases, removes the last five Cterminal amino-acid residues of Sm-F. Cleavage at this position leaves the Sm motifs intact, consistent with the finding that truncated $\mathrm{Sm}-\mathrm{F}$ is associated with the U1 snRNP complexes in apoptotic cells. Antibodies against the TMG cap of the snRNAs, which is removed from the U1 snRNA in apoptotic cells but not from the other snRNAs (U2, U4/U6 and $\mathrm{U} 5),{ }^{22}$ and antibodies against the U2 snRNA associated $\mathrm{B}^{\prime \prime}$ protein were also capable of coimmunoprecipitating the $\mathrm{Sm}-\mathrm{F}$ product from apoptotic Jurkat cell lysates. Therefore, the Sm$F$ protein is probably cleaved not only in the U1 snRNP complex (which is the major autoantigenic complex) but also in the other $U$ snRNP complexes. In agreement with this, the total pool of Sm-F protein appeared to be cleaved in Jurkat cells.

Structural information on the common part of the Sm proteins and on their complexes has been obtained by crystallographic analyses of the $D_{3} B$ and $D_{1} D_{2}$ complexes. ${ }^{29}$
Based upon the experimental data, the Sm proteins were proposed to arrange in a heptamer ring formed by pairwise Sm protein interactions. Interestingly, in this structural model for the Sm complex the C-terminal 11 amino acids of the Sm-F protein (aa 76-86) are predicted to extend from the outer surface of the ring, whereas the RNA component of the $U$ snRNP is positioned in the central hole of the ring. ${ }^{30}$ This structural model is fully consistent with the complete accessibility of the Sm-F cleavage site (aa 81 ) for caspases when the $\mathrm{Sm}-\mathrm{F}$ protein is assembled into $U$ snRNPs.

We have tried to address the nature of the caspase implicated in Sm-F cleavage by treating apoptotic cells with different synthetic tetrapeptide caspase inhibitors and by using a panel of purified recombinant caspases in vitro. Based on these results caspase- 8 appeared to be a good candidate protease for Sm-F cleavage in the apoptotic cell, since it was the most efficient protease in generating the $9 \mathrm{kDa}$-fragment in vitro. However, the generation of this Sm-F fragment in apoptotic lysates of caspase-8-deficient Jurkat cells treated with staurosporin and the results from the peptide inhibitor studies in apoptotic cells (Figure 4), demonstrated that other caspase than caspase- 8 are implicated in $\mathrm{Sm}-\mathrm{F}$ proteolysis as well. We conclude that care should be taken when comparing in vitro and in vivo caspase cleavage data for cellular substrates. In a cellular context, accessibility of the cleavage site in the substrate and subcellular localization likely are principal determinants in defining a caspasesubstrate pair.

Cleavage of Sm-F occurs at the rather unconventional caspase cleavage site EEED ${ }^{81}$. The optimal tetrapeptide sequence for recognition by caspase-8, for instance, has been determined to be $\operatorname{LE}(T / \mathrm{V}) \mathrm{D}$ and for caspase-1 
a

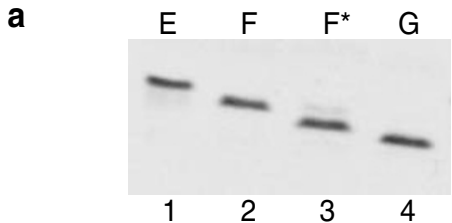

b

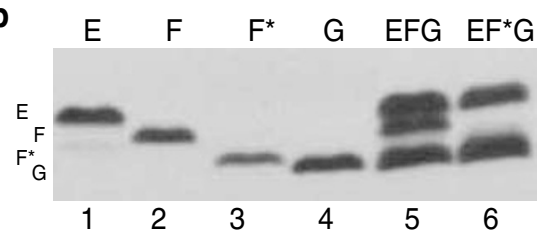

C $\quad E \quad F \quad F^{*} \quad G \quad E F G \quad E F^{*} G$

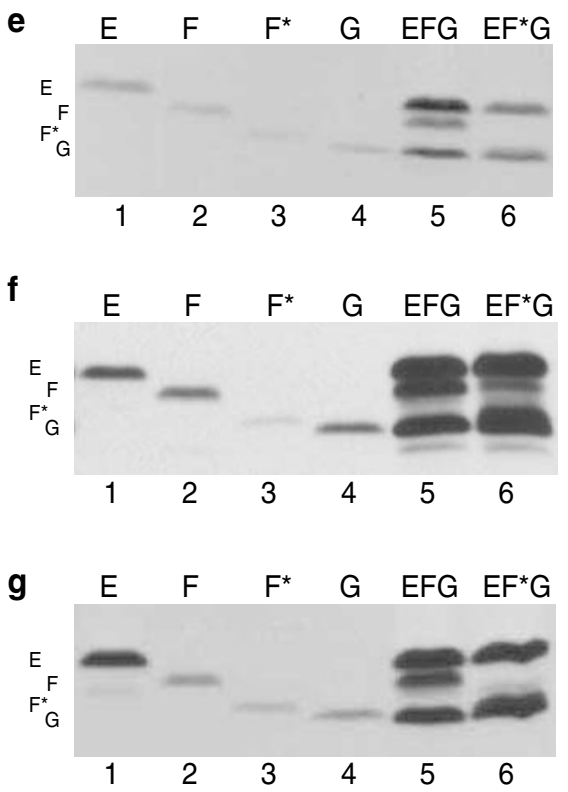

h



Figure 7 Immunoprecipitation of $\mathrm{Sm}-\mathrm{E}, \mathrm{F}, \mathrm{F} \Delta 81$, and $\mathrm{G}$ proteins with selected anti-Sm systemic lupus erythematosus patient sera. Proteins were prepared by in vitro translation in the presence of ${ }^{35} \mathrm{~S}$-methionine. Immunoprecipitates were analyzed by $15 \%$ SDS-PAGE, followed by autoradiography. (a) Proteins equivalent to $20 \%$ of the amount used in the immunoprecipitation assays. Monoclonal antibody $Y 12$ or patient sera were incubated with $S m-E\left(E\right.$, lane 1), Sm-F $\left(F\right.$, lane 2), Sm-F $\Delta 81\left(F^{*}\right.$, lane 3), $S m-G$ (G, lane 4), a preincubated mixture of Sm-E, Sm-F and Sm-G (EFG, lane 5), or a preincubated mixture of Sm-E, Sm-F $\Delta 81$, and $S m-G\left(E F{ }^{\star} G\right.$, lane 6). The $S L E$ sera used were B156 (b), B70 (c), K22 (d), L150 (e), P149 (f), whereas MAb Y12 was used for the immunoprecipitations shown in panel (g). The specificity of the immunoprecipitations was demonstrated with a nonimmune serum tested in parallel with the patient sera $(\mathbf{h})$

(W/L)EHD, based on screening of combinatorial peptide libraries. ${ }^{31,32}$ Nonetheless, caspase cleavage at unconventional sites, including EEED ${ }^{170}$ in DNA topoisomerase 1 , has already been reported previously. ${ }^{33,34}$

The Sm proteins are essential for the splicing of pre-mRNAs in eukaryotes. ${ }^{15}$ The significance of $\mathrm{Sm}-\mathrm{F}$ cleavage for the progression of the apoptotic process is unclear. It has been suggested that cleavage of U1-70K, another component of the autoantigenic U1 snRNP complex, abolishes its function during pre-mRNA splicing as an enhancer of the interaction between the U1 snRNP complex and the $5^{\prime}$-splice site of an exon, thus abrogating the process of mRNA splicing. ${ }^{13,35}$ Whether removal of the carboxyterminal part of Sm-F would impair its function in mRNA splicing will require further studies.

Recent studies have led to the hypothesis that modifications brought upon autoantigens during cell death represent the initial epitopes to which an immune response is generated. ${ }^{1,6}$ Apart from the Sm-F cleavage reported here, three other apoptosis-associated modifications have been described for components of the U1 snRNP complex, a major autoantigen in SLE and SLE-overlap syndromes. These modifications are cleavage of the U1-70K protein ${ }^{21}$, hyperphosphorylation of the associated SR proteins, ${ }^{36}$ and cleavage of the U1 snRNA. ${ }^{22}$ Exposure of elevated and persistent levels of apoptotically modified U1 snRNP to the immune system of a susceptible individual could lead to breaking of the immunological tolerance to the U1 snRNP complex, with subsequent production of autoantibodies to components of this complex in patients with SLE and SLE-overlap syndromes. $^{1,2,6}$ It has been demonstrated recently that autoantibodies specific for the apoptotic form of U1-70K exist even in patient sera without autoantibodies to the complete U1$70 \mathrm{~K}^{37}$ This indicates that the apoptotic form of $\mathrm{U} 1-70 \mathrm{~K}$ displays $\mathrm{B}$ cell epitopes that are not displayed on the fulllength $\mathrm{U} 1-70 \mathrm{~K}$ and that an immune response to apoptotic U1$70 \mathrm{~K}$ may precede responses to intact $\mathrm{U} 1-70 \mathrm{~K}$. This report clearly shows that immunity to apoptotically modified proteins can develop against caspase-cleaved forms of autoantigenic proteins. $^{37}$

Interestingly, many anti-Sm patient sera recognize the modified form of $S m-F$, individually or in the $E-F^{\star}-G$ complex, as demonstrated by immunoblot and immunoprecipitation data obtained with the truncated mutant Sm-F $\Delta 81$. We have tried to demonstrate the relevance of Sm-F cleavage for antiSm autoimmunity in several ways without conclusive results. A possible explanation is that autoantibodies specifically targeting the modified form of Sm-F reported here are only prominently present in patient sera during early stages of the 
disease, since the modified epitopes are supposed to trigger the autoimmune response. The anti-Sm sera we used were of established SLE patients, but future approaches, including the use of serum samples of patients in a very early phase of the disease, could provide evidence that cleavage of Sm-F contributes to breaking of the immunological tolerance to the $\mathrm{Sm}$ proteins and the subsequent generation of anti-Sm autoantibodies in SLE patients.

\section{Materials and Methods}

\section{Cell lines}

Jurkat cells (human T-cell leukemia), control JA3 and caspase-8-deficient Jurkat cells (kindly provided by Dr. J Blenis), Ramos B cells (Burkitt's lymphoma), CCRF-CEM and MOLT-4 (human T-cell lymphoblastic leukemia cell lines), and Jurkat JB6 cells (kindly provided by Dr. S Nagata and Dr. H Matumura) were grown in RPMI-1640 medium (Gibco$\mathrm{BRL}$ ) supplemented with $10 \%$ heat-inactivated fetal calf serum (FCS), $1 \mathrm{mM}$ sodium-pyruvate, penicillin, and streptomycin. Jurkat cells stably transfected with Bcl-2 (Jurkat/Bcl-2) (kindly provided by Dr. J Reed, La Jolla, CA, USA) or with the empty transfection vector (Jurkat/Neo) were cultured in the same medium with the addition of $200 \mu \mathrm{g} / \mathrm{ml} \mathrm{G418} \mathrm{(Gibco-}$ $\mathrm{BRL}$ ). HeLa (human cervix carcinoma) cells and HEp-2 (human larynx carcinoma) cells were grown in DMEM supplemented with $10 \%$ heatinactivated FCS, penicillin, and streptomycin. Cells were cultured in $5 \%$ $\mathrm{CO}_{2}$ at $37^{\circ} \mathrm{C}$.

\section{Patient serum samples}

Serum samples were provided by patients with SLE seen at the Department of Rheumatology and Internal Medicine of the University Medical Center St Radboud, Nijmegen, The Netherlands. Diagnoses were reached as described previously by De Rooij et al. ${ }^{38}$

\section{Induction of cell death}

To induce apoptosis, Jurkat cells were treated with the agonistic anti-Fas monoclonal antibody 7C11 supernatant (final dilution of 1:500) (kindly provided by Dr. M Robertson, Bloomington, IN, USA), ${ }^{23}$ with murine Fasligand supernatant as described ${ }^{22}$ (final dilution of $1: 30$ ) (gift of Dr. A Fontana, Zürich, Switzerland), with $10 \mu \mathrm{g} / \mathrm{ml}$ anisomycin or with $100 \mu \mathrm{g} / \mathrm{ml}$ cycloheximide. HeLa cells and HEp-2 cells were treated with $0.5 \mu \mathrm{g} / \mathrm{ml}$ actinomycin D and anti-Fas antibody or with actinomycin D and $5000 \mathrm{IU} / \mathrm{ml}$ recombinant human TNF $\alpha$. Ramos and CCRF-CEM were treated with actinomycin D, anisomycin, and cycloheximide. CCRF-CEM cells were also treated with anti-Fas antibody. Apoptosis was induced in the MOLT-4 cells by $\gamma$-irradiation using a dose of 5 Gy. Control JA3 and caspase-8deficient Jurkat cells were treated with staurosporin $(400 \mathrm{nM})$ and cycloheximide $(10 \mu \mathrm{g} / \mathrm{ml})$. The extent of induced apoptosis was assessed by flow cytometry using annexin V-FITC and propidium iodide (PI) staining as described previously. ${ }^{22,23}$ After $8 \mathrm{~h}$ generally more than $90 \%$ of the cells were apoptotic. Jurkat JB6 cells were induced to necrosis by treatment with dsRNA (polyl,C) as described elsewhere. ${ }^{27}$ Cells were incubated at $37^{\circ} \mathrm{C}$ for $2-24 \mathrm{~h}$ prior to harvesting. After induction of cell death, cells were washed two times with PBS and used immediately or stored at $-70^{\circ} \mathrm{C}$. For experiments utilizing the cell-permeable tetrapeptide caspase inhibitors (Calbiochem), Jurkat cells were cultured for $1 \mathrm{~h}$ in the presence of 2 or $20 \mu \mathrm{M} \mathrm{Ac-YVAD-CMK,} \mathrm{Z-DEVD-FMK,} \mathrm{Z-IETD-FMK,} \mathrm{or} \mathrm{Z-LEHD-}$ FMK (irreversible inhibitors of caspases $-1,-3 /-7,-8$, and -9 , respectively) in dimethylsulfoxide (DMSO). The specificity of these inhibitors is based on in vitro assays with purified caspases and in this way their specificity in a cellular context is difficult to define. Subsequently, apoptosis was induced by the addition of anti-Fas monoclonal antibody followed by harvesting the cells after $8 \mathrm{~h}$ of incubation.

\section{Western blot analysis}

Cells were lysed on ice for $30 \mathrm{~min}$ in NP-40 lysis buffer $(25 \mathrm{mM}$ Tris- $\mathrm{HCl}$, $\mathrm{pH} 7.5,1 \% \mathrm{NP}-40,100 \mathrm{mM} \mathrm{KCl}, 10 \mathrm{mM} \mathrm{MgCl}_{2}, 1 \mathrm{mM}$ dithiothreitol (DTT)), containing a protease inhibitor cocktail (Roche). Cell lysates were centrifuged for $15 \mathrm{~min}$ at $4^{\circ} \mathrm{C}(12000 \mathrm{~g})$ and the supernatants were used immediately or stored at $-70^{\circ} \mathrm{C}$. Protein extracts of $1 \times 10^{6}$ cells were analyzed by $15 \%$ SDS-PAGE and Western blotting using SLE patient serum B156 (anti-Sm-F) or H42 (anti-U1-70K), anti-SmF rabbit serum (kindly provided by Dr. Reinhard Lührman and Dr. Hero Brahms, MaxPlanck Institute of Biophysical Chemistry, Göttingen, Germany) or anticaspase- 8 mouse mAb (PharMingen, San Diego, CA, USA), followed by detection by chemoluminescence.

\section{Immunoprecipitation}

Protein A-agarose beads ( $20 \mu \mathrm{l}$ of $50 \%$ slurry, Pharmacia) were coated with $200 \mu \mathrm{l}$ culture supernatant of the following mouse monoclonal antibodies: Y12 (anti-SmB/B'/D1/D3), ${ }^{39} \mathrm{KSm} 2$ (anti-SmD1), ${ }^{40} 2.73$ (antiU1-70K), ${ }^{41} 9 A 9$ (anti-U1A/U2B'), 4G3 (anti-U2B' $), 2$ G10 (anti-Ro60), or with $20 \mu \mathrm{g}$ of anti-2,2,7-trimethylguanosine (TMG) cap rabbit polyclonal antibodies (H20) (Euro-Diagnostica BV, Arnhem, The Netherlands). Incubations were performed overnight at $4^{\circ} \mathrm{C}$ in IPP150 (150 mM NaCl, $10 \mathrm{mM}$ Tris- $\mathrm{HCl} \mathrm{pH} \mathrm{8.0,0.1 \%} \mathrm{NP-40)} \mathrm{by} \mathrm{end-over-end} \mathrm{rotation.} \mathrm{Between}$ incubations, beads were washed three times with IPP150. Immunoprecipitations were carried out with $20 \mu \mathrm{l}\left(2 \times 10^{6}\right.$ cell equivalents) of Jurkat extract (control or apoptotic) in IPP150 by end-over-end rotation for $2 \mathrm{~h}$ at $4^{\circ} \mathrm{C}$ and subsequently washed three times with IPP150. The beads were resuspended in Laemmli buffer to analyze protein complexes using SDSPAGE and Western blotting.

\section{Plasmids}

A full-length cDNA of Sm-F cloned into the EcoRI and Sall sites of pBluescript KS+ vector (pBLSF) was kindly provided by Dr. Reinhard Lührmann and Dr. Hero Brahms (Max-Planck Institute of Biophysical Chemistry, Göttingen, Germany). Two mutant cDNAs were generated, one encoding a C-terminally truncated $\mathrm{Sm}-\mathrm{F}$ protein ( $\mathrm{F} \Delta 81$ ), which corresponds to the largest apoptotic $\mathrm{Sm}-\mathrm{F}$ fragment generated in vivo, and another encoding a substitution mutant of $\mathrm{Sm}-\mathrm{F}$ in which the aspartic acid at position 81 was substituted by an alanine. Both mutants were generated by a PCR-based approach using pBLSF as a template and the following primers: 5'-GCGAATTCCACCATGAGTTTACCCCTCAATCCC-3' (corresponding to the N-terminal region of Sm-F; EcoRl site underlined), 5'-CCGTCGACCTATTCTCTCATTTCCCCAGCTTCTTCCT-3' (to generate the substitution mutant; Sall site underlined; mutation in bold), and $5^{\prime}$ CTGCCGGTCGACCTAATCTTCTTCCTCTTCTTCCAC-3' (to generate the deletion mutant; Sall site underlined). The resulting PCR products were purified, digested with $E c o R I$ and Sall and were inserted into the $\mathrm{EcoRI}$ and Sall sites of pBluescript KS-. The integrity of the mutant constructs was confirmed by DNA sequencing. The pBLSE, pBLSG (kindly provided by Reinhard Lührmann, Göttingen, Germany), and pGemPARP constructs, which contain the complete human Sm-E, Sm-G, 
and PARP cDNAs, respectively, were used as template for transcription/ translation of the respective proteins.

\section{Immunoprecipitation of in vitro translated proteins}

Proteins were generated by in vitro transcription/translation of $\mathrm{pBLSE}$, pBLSF, pBLSG, and pBLSF $\Delta 81$ templates using the TnT T7-coupled rabbit reticulocyte lysate system (Promega) as described by the manufacturer. For detection of the translation products, ${ }^{35}$ S-methionine was added to the translation reactions. For each immunoprecipitation, $5 \mu \mathrm{l}$ of in vitro translated $\mathrm{E}, \mathrm{F}, \mathrm{G}$, and/or $\mathrm{F} \Delta 81$ protein were incubated, either alone or in the combinations stated in the text, for $45 \mathrm{~min}$ at $30^{\circ} \mathrm{C}$. A measure of $5 \mu \mathrm{l}$ of patient serum or of a normal human serum (as the negative control for each experiment) or $100 \mu \mathrm{l}$ of culture supernatant of anti-Sm Y12 was then added to the radiolabeled protein sample, and the incubation was continued for an additional $30 \mathrm{~min}$ at room temperature. The mixture was transferred to another tube containing $10 \mu \mathrm{l}$ of preswollen protein G-agarose (Pharmacia) in $400 \mu \mathrm{l}$ of $\mathrm{PBS} / 1 \%$ bovine serum albumin. Following incubation for $2 \mathrm{~h}$ at $4{ }^{\circ} \mathrm{C}$ with gentle agitation, the beads were washed five times with $10 \mathrm{mM}$ Tris- $\mathrm{HCl}$, $\mathrm{pH} 7.5,0.05 \% \mathrm{NP}-40,150 \mathrm{mM} \mathrm{NaCl}$, and once with water. Precipitated proteins were fractionated on $15 \%$ SDS-PAGE and visualized by autoradiography.

\section{In vitro cleavage assay}

In vitro translated Sm-F, Sm-F-D81A (substitution mutant), and PARP were incubated with $200 \mathrm{nM}$ of the purified murine recombinant caspases $^{28}$ in a total volume of $25 \mu \mathrm{l}$ CFS buffer $(220 \mathrm{nM}$ mannitol, $68 \mathrm{nM}$ sucrose, $2 \mathrm{mM} \mathrm{NaCl}, 2.5 \mathrm{mM} \mathrm{KH}_{2} \mathrm{PO}_{4}, 10 \mathrm{nM} \mathrm{HEPES} \mathrm{pH} \mathrm{7.4,} 1 \mathrm{mM}$ aprotinin, $1 \mathrm{mM}$ leupeptin, and $1 \mathrm{mM}$ PMSF, supplemented with $5 \mathrm{mM}$ $\mathrm{DTT}$ ) for $1.5 \mathrm{~h}$ at $37^{\circ} \mathrm{C}$. The resulting cleavage products were analyzed by $15 \%$ SDS-PAGE, followed by autoradiography. To compare the enzymatic activities of caspases- $1,-8$, and -3 on the Sm-F protein more accurately, a serial dilution of the enzymes $(200,66$, and $22 \mathrm{nM})$ was incubated with the radiolabeled proteins in a total volume of $25 \mu \mathrm{l}$.

\section{Acknowledgements}

We are grateful to Dr. Reinhard Lührmann and Dr. Hero Brahms (MaxPlanck Institute of Biophysical Chemistry, Göttingen, Germany) for the fulllength cDNA of Sm-E, Sm-F, and Sm-G proteins and for rabbit anti-Sm polyclonal sera. We thank Dr. J Reed (Burnham Institute, La Jolla, CA, USA) for the Jurkat/Neo and Jurkat/ Bcl-2 cell lines; Dr. M Robertson (Indiana University, Bloomington, IN, USA) for the anti-Fas mAb 7C11; Dr. A. Fontana (Zürich, Switzerland) for the mouse Neuro2A cells used for production of murine Fas-ligand; Dr. J Blenis (Department of Cell Biology, Harvard Medical School, Boston, MA, USA) for the capase-8-deficient Jurkat cells; and Dr. S Nagata and Dr. H Matumura (Department of Genetics, Osaka University Medical School, Suita, Japan) for Jurkat JB6 cells. This work was supported in part by the Netherlands Organization for Scientifc Research (NWO-CW). The work of XS and PV is supported by the Interuniversitaire Attractiepolen (IUAP-V), the Fonds voor Wetenschappelijk Onderzoek-Vlaanderen (Grants 31.5189 .00 and 3G.0006.01) and the EC-RTD (Grant QLRT-1999-00739). XS is paid by the Biotech fund.

\section{References}

1. Utz PJ and Anderson P (1998) Posttranslational protein modifications, apoptosis, and the bypass of tolerance of autoantigens. Arthritis Rheum. $41: 1152-1160$

2. Rosen A and Casciola-Rosen L (1999) Autoantigens as substrates for apoptotic proteases: implications for the pathogenesis of systemic autoimmune disease. Cell Death Differ. 6: 6-8

3. Utz PJ, Gensler TJ and Anderson P (2000) Death, autoantigen modifications, and tolerance. Arthritis Res. 2:101-104

4. Rovere P, Sabbadini MG, Fazzini F, Bondanza A, Zimmermann VS, Rugarli C and Manfredi AA (2000) Remnants of suicidal cells fostering systemic autoaggression. Apoptosis in the origin and maintenance of autoimmunity. Arthritis Rheum. 43: 1663-1672

5. Degen WGJ, Pruijn GJM, Raats JMH and van Venrooij WJ (2000) Caspasedependent cleavage of nucleic acids. Cell Death Differ. 7: 616-627

6. Rodenburg RJT, Raats JMH, Pruijn GJM and van Venrooij WJ (2000) Cell death: a trigger of autoimmunity?. BioEssays 22:627-636

7. Doyle HE and Mamula MJ (2001) Post-translational protein modifications in antigen recognition and autoimmunity. Trends Immunol. 22: 443-449

8. Wu X, Molinaro C, Johnson N and Casiano C (2001) Secondary necrosis is a source of proteolytically modified forms of specific intracellular autoantigens. Arthritis Rheum. 44: 2642-2652

9. Stennicke HR and Salvesen GS (1998) Properties of the caspases. Biochim. Biophys. Acta 1387:17-31

10. Stroh C and Schulze-Osthoff K (1998) Death by a thousand cuts: an ever increasing list of caspase substrates. Cell Death Differ. 5: 997-1000

11. Andrade F, Roy S, Nicholson D, Thornberry N, Rosen A and Casciola-Rosen L (1998) Granzyme B directly and efficiently cleaves several downstream caspase substrates: implications for CTL-induced apoptosis. Immunity 8: 451460

12. Casciola-Rosen L, Andrade F, Ulanet D, Wong WB and Rosen A (1999) Cleavage by granzyme $B$ is strongly predictive of autoantigen status: implications for initiation of autoimmunity. J. Exp. Med. 190:815-826

13. Trapani JA, Davis J, Sutton VR and Smyth MJ (2000) Proapoptotic functions of cytotoxic lymphocyte granule constituents in vitro and in vivo. Curr. Opin. Immunol. 12: 323-329

14. Klein Gunnewiek JMT, van de Putte LBA and van Venrooij WJ (1997) The U1 snRNP complex: an autoantigen in connective tissue diseases. Clin. Exp. Rheumatol. 15: 549-560

15. Will CL and Lührmann R (2001) Spliceosomal U snRNP biogenesis, structure and function. Curr. Opin. Cell Biol. 13: 290-301

16. Hermann $H$, Fabrizio $P$, Raker VA, Foulaki K, Hornig $H$, Brahms $H$ and Lührmann R (1995) snRNP Sm proteins share two evolutionary conserved motifs which are involved in Sm protein-protein interactions. EMBO J. 14 2076-2088

17. Lehmeier T, Foulaki $K$ and Lührmann $R$ (1990) Evidence for three distinct $D$ proteins, which react differentially with anti-Sm autoantibodies, in the cores of the major snRNPs U1, U2, U4/U6 and U5. Nucleic Acids Res. 18: 6475-6484

18. Reuter R, Rothe S, Habets W, van Venrooij WJ and Lührmann R (1990) Autoantibody production against the $U$ small nuclear ribonucleoprotein particle proteins $\mathrm{E}, \mathrm{F}$, and $\mathrm{G}$ in patients with connective tissue diseases. Eur. J. Immunol. 20: 437-440

19. Brahms H, Raker VA, van Venrooij WJ and Lührmann R (1997) A major, novel systemic lupus erythematosus autoantibody class recognizes the E-F-G complex but not in their denatured states. Arthritis Rheum. 40: 672-682

20. Scaffidi C, Fulda S, Srinivasan A, Friesen C, Li F, Tomaselli KJ, Debatin KM, Krammer PH and Peter ME (1998) Two CD95 (APO-1/Fas) signalling pathways. EMBO J. 17: 1675-1687

21. Casciola-Rosen LA, Miller DK, Anhalt GJ and Rosen A (1994) Specific cleavage of the $70-\mathrm{kDa}$ protein component of the U1 small nuclear ribonucleoprotein is a characteristic biochemical feature of apoptotic cell death. J. Biol. Chem. 269:30757-30760

22. Degen WGJ, van Aarssen Y, Pruijn GJM, Utz PJ and van Venrooij WJ (2000) The fate of U1 snRNP during anti-Fas induced apoptosis: specific cleavage of the U1 snRNA molecule. Cell Death Differ. 7: 70-79

23. Rutjes SA, Utz PJ, van der Heijden A, Broekhuis $C$, van Venrooij WJ and Pruijn GJM (1999) The La (SS-B) autoantigen, a key protein in RNA biogenesis, is dephosphorylated and cleaved during apoptosis. Cell Death Differ. 6: 976-986 
24. Denecker G, Vercammen D, Declercq W and Vandenabeele P (2001) Apoptotic and necrotic cell death induced by death domain receptors. Cell Molec. Life Sci. 58: 356-370

25. Denecker G, Vercammen D, Steemans M, Vanden Berghe T, Brouckaert G Van Loo G, Zhivotovsky B, Fiers W, Grooten J, Declercq W and Vandenabeele $P(2001)$ Death receptor-induced apoptotic and necrotic cell death: differentia role of caspases and mitochondria. Cell Death Differ. 8: 829-840

26. Kawahara A, Ohsawa Y, Matsumura H, Uchiyama Y and Nagata S (1998) Caspase-independent cell killing by Fas-associated protein with death domain. J Cell Biol. 143: 1353-1360

27. Kalai M, Van Loo G, Vanden Berghe T, Meeus A, Burm W, Saelens X and Vandenabeele $P(2002)$ Tipping the balance between necrosis and apoptosis in human and murine cells treated with interferon and dsRNA. Cell Death Differ. 9: 981-994

28. Van de Craen M, Declercq W, Van den Brande I, Fiers W and Vandenabeele P (1999) The proteolytic procaspase activation network: an in vitro analysis. Cell Death Differ. 6: 1117-1124

29. Kambach C, Walke S, Young R, Avis JM, de la Fortelle E, Raker VA, Lührmann R, Li J and Nagai K (1999) Crystal structures of two Sm protein complexes and their implication for the assembly of the spliceosomal snRNPs. Cell 96: 375387

30. Törö I, Thore S, Mayer C, Basquin J, Seraphin B and Suck D (2001) RNA binding in an Sm core domain: X-ray structure and functional analysis of an archaeal Sm protein complex. EMBO J. 20, 2293-2303

31. Thornberry NA, Rano TA, Peterson EP, Rasper EM, Timkey T, Garcia-Calvo M Houtzager VM, Nordstrom PA, Roy S, Vaillancourt JP, Chapman KT and Nicholson DW (1997) A combinatorial approach defines specificities of members of the caspase family and granzyme B. Functional relationships established for key mediators of apoptosis. J. Biol. Chem. 272: 17907-17911

32. Thornberry NA, Chapman KT and Nicholson DW (2000) Determination of caspase specificities using a peptide combinatorial library. Methods Enzymol. 322: $100-110$
33. Samejima K, Svingen PA, Basi GS, Kottke T, Mesner Jr PW, Stewart L, Durrieu F, Poirier GG, Alnemri ES, Champoux JJ, Kaufmann SH and Earnshaw WC (1999) Caspase-mediated cleavage of DNA topoisomerase I at unconventional sites during apoptosis. J. Biol. Chem. 274: 4335-4340

34. Affar EB, Germain M, Winstall E, Vodenicharov M, Shah RG, Salvesen GS and Poirier GG (2001) Caspase-3-mediated processing of poly(ADP-ribose) glycohydrolase during apoptosis. J. Biol. Chem. 276: 2935-2942

35. Tazi J, Kornstadat U, Rossi F, Jeanteur P, Cathala G, Brunel $C$ and Lührmann R (1993) Thiophosphorylation of U1-70K protein inhibits pre-mRNA splicing. Nature 363: 283-286

36. Utz PJ, Hottelet M, van Venrooij WJ and Anderson P (1998) Association of phosphorylated serine/arginine (SR) splicing factors with the U1-small ribonucleoprotein (snRNP) autoantigen complex accompanies apoptotic cell death. J. Exp. Med. 187: 547-560

37. Greidinger EL, Foecking MF, Ranatunga S and Hoffman RW (2002) Apoptotic U1-70 kd is antigenically distinct from the intact form of the U1-70 kd molecule. Arthritis Rheum. 46: 1264-1269

38. De Rooij DJ, van de Putte LB, Habets WJ, Verbeek AL and van Venrooij WJ (1988) The use of immunoblotting to detect antibodies to nuclear and cytoplasmic antigens. Clinical and serological associations in rheumatic diseases. Scand. J. Rheumatol. 17: 352-364

39. Lerner EA, Lerner MR, Janeway Jr CA and Steitz JA (1981) Monoclonal antibodies to nucleic acid-containing cellular constituents: probes for molecular biology and autoimmnune disease. Proc. Natl. Acad. Sci. USA 78: 2737-2741

40. Williams DG, Stocks MR, Smith PR and Maini RN (1986) Murine lupus monoclonal antibodies define five epitopes on two different Sm polypeptides. Immunology 58: 495-500

41. Billings PB, Allen RW, Jensen FC and Hoch SO (1982) Anti-RNP monoclonal antibodies derived from a mouse strain with lupus-like autoimmunity. J. Immunol. 128: 1176-1180 